\title{
Psychological Pressure in Competitive Environments: Evidence from a Randomized Natural Experiment
}

\author{
By Jose Apesteguia and Ignacio Palacios-Huerta*
}

Much as the rationality principle has successfully accommodated social attitudes, altruism, values, and other elements (see, e.g., Gary S. Becker 1976, 1996; Becker and Kevin M. Murphy 2000), behavioral economics attempts to parsimoniously incorporate psychological motives not traditionally included in economic models. Theoretical models in this area firmly rely for empirical support on the observation of human decision making in laboratory environments. Laboratory experiments have the important advantage of providing a great deal of control over relevant margins. In these settings, observed behavior often deviates from the predictions of standard economic models. In fact, at least since the 1970s, a great deal of experimental evidence has been accumulated demonstrating circumstances under which strict rationality considerations break down and other patterns of behavior, including psychological considerations, emerge. Thus, an important issue is how applicable are the insights gained in laboratory settings for understanding behavior in natural environments. This challenge, often referred to as the problem of "generalizability" or "external validity," has assumed a central role in recent research in the area.

The best and perhaps only way to address this concern is by studying human behavior in real life settings. Unfortunately, however, Nature seldom creates the circumstances that allow a clear view of the psychological principles at work. Furthermore, naturally occurring phenomena are typically too complex to be empirically tractable in a way that allows us to discern psychological elements from within the characteristically complex behavior exhibited by humans.

In this paper we take advantage of an unusually clean opportunity to discern these elements by studying a randomized natural experiment, that is, a real life situation in which the treatment and control groups are determined via explicit randomization. As is well known, this situation guarantees internal validity since it satisfies the conditions for causal inference (Charles F. Manski 1995). The subjects in the experiment are professionals who have to perform a simple task in a tournament competition. In soccer, one of the methods of determining the winning team if a match is drawn but a winner is needed is by the two teams taking kicks from the penalty mark. This method is used worldwide in all major elimination tournaments involving both national and club teams (e.g., World Cups, European Cups, Champions League, etc). From the time it was first introduced in 1970 and until 2003, the basic procedure established that both teams alternately take five penalty kicks each, and that the order of the kicks be decided by a referee who tosses $a$ coin, and the team whose captain wins the toss takes the first kick.

\footnotetext{
*Apesteguia: Department of Economics, Universitat Pompeu Fabra, Ramon Trias Fargas, 08005 Barcelona, Spain (e-mail: jose.apesteguia@upf.edu); Palacios-Huerta: Department of Management, London School of Economics, Houghton Street, London WC2A 2AE, United Kingdom (e-mail: i.palacios-huerta@1se.ac.uk). We thank three anonymous referees, Ghazala Azmat, Miguel A. Ballester, Jordi Blanes-i-Vidal, Caterina Calsamiglia, Juan D. Carrillo, Gary Charness, Yeon-Koo Che, Pedro Dal Bo, David de Meza, Manuel E. Mejuto, Patxo Palacios, Steve Pischke, Antonio Rangel, Pedro Rey, Yona Rubinstein, Giulio Seccia, Carmit Segal, and participants in various seminars and conferences for helpful comments. Ozan Eksi provided excellent research assistance and Eugenio J. Miravete the programs that implement the dynamic panel data analysis. We gratefully acknowledge financial support from the Fundación Ramón Areces, the Spanish Ministerio de Ciencia y Tecnología (grant SEJ2006-11510), the Barcelona GSE research network, and the Government of Catalonia, as well as the editing assistance from Estelle Shulgasser.
} 
This randomized experiment gives us the chance to study a situation that is familiar to the subjects and takes place in the natural setting in which they operate. The subjects are professionals; in fact, they are among the highest paid professionals in the world, and the task they have to perform (kick a ball once) is one of the simplest they could possibly be asked to perform. Further, the competitive setting relates to an important framework of analysis in labor economics and in the economics of organizations (the tournament model). Moreover, from an empirical perspective all the relevant variables are perfectly observable, the task is effortless, outcomes are decided immediately, and with only two possible outcomes (score, no score) risk plays no role in the analysis. Finally, individuals are subject to high incentives, and so are interested in performing as well as they can. In fact, their actions often have enormous consequences not only for their individual careers, but also for their team, their city, and even their country, as in a World Cup final, for instance.

The explicit randomization mechanism used to determine which team goes first in the sequence, in a situation where both teams have exactly the same opportunities to perform a task, suggests that we should expect the first and second teams to have exactly the same probability of winning the tournament. Yet, we find a strongly significant and quantitatively important difference. Using data on 1,343 penalty kicks from 129 penalty shoot-outs over the period 1976-2003, we find that teams that take the first kick in the sequence win the penalty shoot-out 60.5 percent of the time. Given the characteristics of the setting we can attribute this difference in performance to psychological effects resulting from the consequences of the kicking order.

The paper is structured as follows. Section I briefly reviews relevant literature. Section II presents the natural experiment. Section III describes the data and reports the main empirical result. In Section IV we study whether subjects are aware of the advantage of going first, whether they rationally respond to it by systematically choosing to kick first when given the chance to choose the order, and whether, when surveyed, they identify a specific psychological mechanism for their behavior. We find that the answer to these three questions is affirmative. We also study the mechanism whereby teams kicking first are more likely to win using a random effects dynamic panel data model and discuss some policy implications. Section V concludes.

\section{Related Literature}

This paper relates to several strands of literature in economics and psychology. First, the natural setting is that of a tournament. Tournaments are pervasive in real life and often characterize competitive situations such as competitions for promotion in internal labor markets in firms and organizations, patent races, political elections, student competitions in schools, and many others. The tournament model was first formalized by Edward P. Lazear and Sherwin Rosen (1981), and over the last couple of decades a large literature has studied both theoretically and empirically a number of important aspects of this incentive scheme. Despite the large body of work, however, we are aware of no evidence documenting how psychological or emotional effects may be relevant in explaining the performance of subjects competing in a tournament setting. One possible reason for this is that the difficulties in clearly observing actions, outcomes, choices of risky strategies, and other relevant variables in naturally occurring settings are exceedingly high, and as a result it is not possible to discern with sufficient precision whether there are, in addition to these variables, any psychological elements at work.

The characteristics of the setting we study, however, are ideal for overcoming these obstacles. Variables such as the choice of effort levels and risky strategies that are typically hard to

\footnotetext{
${ }^{1}$ See Canice Prendergast (1999) for a review.
} 
measure in tournaments and other competitive situations play no role in our setting: the task (kicking a ball once) involves no physical effort and, with only two possible outcomes (score or no score), risk plays no role either. ${ }^{-}$Outcomes can be perfectly observed and are immediately determined after players make their choices; that is, there is no subsequent play. This is important, indeed critical, to establish the empirical results. ${ }^{3}$ Furthermore, the rules of the competition are precisely established and require that subjects are always in the same physical situation (same position and location).

Second, an important literature in social psychology has studied expert performance and performance under pressure such as that induced by high stakes, the presence of an audience, and others. ${ }^{-1}$ Dan Ariely, Uri Gneezy, George Loewenstein, and Nina Mazar (2009) review and discuss this literature in the context of a study of whether or not increases in motivation and effort result in improved performance. In our setting, however, both teams have the same stakes in the shoot-out, and both perform in front of the same audience, an audience which in many shoot-outs roughly equally supports both teams. More importantly, although different forms of pressure (e.g., stakes, audience) may be complements with each other, the explicit randomization procedure that is used means that there is no reason why one team should be systematically more affected than the other. The novel result we obtain from the perspective of this literature is that differences in the interim state of the competition caused by the kicking order may generate differences in the psychological pressure that drives the effects on performance that we observe.

Third, there is a literature showing the importance of psychology to economics. Stefano DellaVigna (2009) surveys the empirical evidence from natural settings documenting deviations from the standard rational model with respect to nonstandard preferences, incorrect beliefs, and systematic biases in decision making. It has been shown, for instance, that behavior often depends on reference points. In our setting, as will be documented later, the score at the time a player has to perform his task (the state of the competition) appears to act as a reference point, and the "ahead-behind" asymmetry associated with this partial score (that is, to be leading or

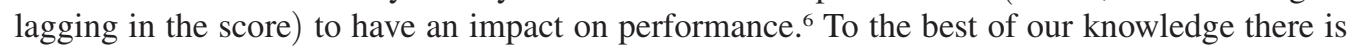
no empirical evidence from real life strictly competitive environments on reference-dependent preferences and their impact on performance. Similarly, we are aware of no empirical evidence documenting how changes in mood and arousal associated with the state of the competition can generate deviations from the rational model in terms of performance. ] $^{\text {T }}$

\footnotetext{
${ }^{2}$ The role of risk in tournament competitions has been examined in Hans K. Hvide (2002) and Hvide and Eirik G. Kristiansen (2003). In dynamic competition games, there is a literature on the "increasing dominance" effect of a leader over a rival (e.g., Luis M. B. Cabral 2002, 2003), which studies the strategic choice of variance and covariance throughout a competition.

${ }^{3}$ The reason is that if there were subsequent actions that contribute to determine the outcome, we would need to have detailed information on the subjects' choice of effort levels and choice of risky strategies in those actions. Further, subjects may also have asymmetric information concerning their effort levels and be heterogeneous in their risk attitudes. These aspects mean that situations in which a coin toss is used to decide, for instance, initial sides or which team begins play (see, e.g., V. Bhaskar 2009 and Jan R. Magnus and Franc J. G. M. Klaassen 1999 for studies on cricket and tennis) are an order of magnitude more complex than a penalty kick for discerning the presence of psychological elements. Further, winners of the coin toss in these settings typically choose sides and whether or not to begin batting or serving. This means that these situations do not represent a perfect randomized experiment.

${ }^{4}$ See, for instance, K. Anders Ericsson et al. (2006); Sian Beilock (2007), and other references therein.

${ }^{5}$ We will not speculate as to the actual form that these psychological effects may take beyond indicating that they may be associated with increased arousal, greater shifting of mental process from "automatic" to "controlled," or differences in the narrowing of attention (see Daniel Kahneman 1973). Also, they may represent differences in mental fatigue or mental strain.

${ }^{6}$ See Botond Kőszegi and Matthew Rabin (2006) for a model of reference-dependent preferences where "gain-loss" (or "ahead-behind") evaluations around a reference point influence behavior.

${ }^{7}$ For evidence on the impact of changes associated with exposure to media violence, the weather, and other factors, see DellaVigna (2009). With regard to formal models, Larry G. Epstein and Igor Kopylov (2007) develop a model of pessimism where individuals lose confidence in their outlook as they approach the moment of truth. Theoretical contributions
} 
Lastly, there is some economic literature on the ex post fairness of certain regulations in sports where a coin flip that determines the order of play may have a significant impact on the outcome of a game by giving the winner of the coin flip more chances to perform a task (e.g., Yeon-Koo Che and Terrence Hendershott 2008, for the case of extra-time sudden-death regulations in the National Football League) $₫$ Our results show that even under ideal circumstances where a coin flip determines only the order of competition and both teams have exactly the same chances, human nature is such that the outcome of a perfect randomized trial may be considered ex post unfair.

\section{The Randomized Natural Experiment}

A penalty shoot-out is simply a sequence of penalty kicks. The rules that govern a penalty kick are described in the Official Laws of the Game issued by the world governing body of soccer, the Fédération Internationale de Football Association (FIFA). ${ }^{\square}$ Each penalty kick involves two players: a kicker and a goalkeeper. In the typical kick the ball takes about $0.3-0.4$ seconds to travel the distance between the penalty mark and the goal line, which is less than the reaction time plus the goalkeeper's movement time to possible paths of the ball. Hence, both kicker and goalkeeper must move simultaneously, and the outcome is determined immediately. The penalty kick has only two possible outcomes: score or no score. There are no second penalties or any form of subsequent play in the event of a goal not being scored. By any reasonable metric the task can be considered effortless, and with only two possible outcomes risk plays no role. ${ }^{10}$ Further, players' actions and outcomes can be perfectly observed. The initial location of both the ball and the goalkeeper is always the same: the ball is placed on the penalty mark and the goalkeeper positions himself on the goal line.

The purpose of a penalty shoot-out is to decide the winning team where competition rules require one team to be declared the winner after a drawn match.11 The penalty shoot-out was first introduced in 1970 and until July 2003 its main characteristics were as follows (FIFA 2002, 36):

- "The referee tosses a coin and the team whose captain wins the toss takes the first kick.

- Subject to the conditions explained below, both teams take five kicks.

- The kicks are taken alternately by the teams.

- If, before both teams have taken five kicks, one has scored more goals than the other could score, even if it were to complete its five kicks, no more kicks are taken.

- If, after both teams have taken five kicks, both have scored the same number of goals, or have not scored any goals, kicks continue to be taken in the same order until one team has scored a goal more than the other from the same number of kicks."

In July 2003, FIFA $(2003,36)$ decided to slightly change the first regulation in the procedure by replacing it with (italics added):

- "The referee tosses a coin and the team whose captain wins the toss decides whether to take the first or the second kick."

The focus of our analysis is the period 1970-2003 where we have a perfect randomized experiment, and post-2003 data will be used to assess other relevant aspects.

on anxiety include Loewenstein (1987), Andrew Caplin and John Leahy (2001), and Michael T. Rauh and Giulio Seccia (2006). In cognitive psychology, Larry W. Morris, Mark A. Davis, and Calvin H. Hutchings (1981) provides a review.

${ }^{8}$ Bialik, Carl. 2003. "Should the Outcome of a Coin Flip Mean So Much in NFL Overtime?" The Wall Street Journal, December 23, 2003.

${ }^{9}$ Federation Internationale de Football Association. 2002, 2003, 2007. Official Laws of the Game. Zurich: FIFA.

${ }^{10}$ We refer here to physical effort, which is typically conceived as a choice variable. With regard to mental effort, arousal is the brain's way of increasing its level of effort, and it is not ordinarily under volitional control (see Kahneman 1973).

${ }^{11}$ The complete set of rules in a penalty shoot-out is available at http://www.fifa.com. 
TABle 1 -Description of the Dataset

\begin{tabular}{|c|c|c|c|c|c|c|c|}
\hline \multirow[b]{2}{*}{ Competition } & \multirow[b]{2}{*}{ Type } & \multicolumn{2}{|c|}{$1970-2003$} & \multicolumn{2}{|c|}{$2003-2008$} & \multirow[b]{2}{*}{$\begin{array}{c}\text { All shoot-outs } \\
\qquad N\end{array}$} & \multirow[b]{2}{*}{$\begin{array}{c}\text { All kicks } \\
\qquad N\end{array}$} \\
\hline & & $\begin{array}{c}\text { Shoot-outs } \\
N\end{array}$ & $\begin{array}{c}\text { Kicks } \\
N\end{array}$ & $\begin{array}{c}\text { Shoot-outs } \\
\quad N\end{array}$ & $\begin{array}{c}\text { Kicks } \\
N\end{array}$ & & \\
\hline World Cup & National teams & 16 & 153 & 4 & 33 & 20 & 186 \\
\hline $\begin{array}{l}\text { European } \\
\text { Championship }\end{array}$ & National teams & 9 & 97 & 4 & 42 & 13 & 139 \\
\hline American Cup & National teams & 12 & 116 & 3 & 31 & 15 & 147 \\
\hline African Nations Cup & National teams & 9 & 110 & 4 & 58 & 13 & 168 \\
\hline Gold Cup & National teams & 5 & 55 & 2 & 17 & 7 & 72 \\
\hline Asian Nations Cup & National teams & - & - & 7 & 74 & 7 & 74 \\
\hline Champions League & Clubs & 8 & 82 & 13 & 127 & 21 & 209 \\
\hline UEFA Cup & Clubs & 12 & 101 & 20 & 221 & 32 & 322 \\
\hline Spanish Cup & Clubs & 29 & 308 & 26 & 259 & 55 & 567 \\
\hline German Cups & Clubs & 24 & 273 & 48 & 521 & 72 & 794 \\
\hline English Cups & Clubs & 5 & 48 & 9 & 94 & 14 & 142 \\
\hline All & & 129 & 1,343 & 140 & 1,477 & 269 & 2,820 \\
\hline
\end{tabular}

Notes: The dataset includes all the shoot-outs in the history of the World Cup, European Championship, American Cup, African Nations Cup (except one), and Gold Cup. All these are international competitions for national teams. The European Champions League and European UEFA Cup are international club competitions in Europe. For these two competitions the dataset includes all the shoot-outs that ever took place in the final match and all those that took place in any of the rounds in the period 2000-2008. The Spanish Cup, the German Cups, and the English Cups are national club competitions. For the Spanish Cup and the German Cup the dataset has all the shoot-outs that took place in a final match, plus all the shoot-outs in all the rounds in the period 1999-2008 (Spanish Cup) and in the period 2001-2008 (German Cup). For the German Supercup it includes all those that ever took place. The English Cups include data on the F.A. Cup, League Cup, and the F.A. Community Shield.

\section{Data and Empirical Evidence}

The data come from the Union of European Football Associations (UEFA), the Rec.Sport. Soccer Statistics Foundation, the Association of Football Statisticians, weltfussball.de, and the Spanish newspapers MARCA and El Pais. The dataset comprises 269 penalty shoot-outs with 2,820 penalty kicks over the period 1970-2008 and it includes all the observations available in the Web sites uefa.com, rssf.com, weltfussball.de, elpais.com, and marca.com (last accessed on November 17, 2007). It is fully comprehensive in that it includes all the penalty shoot-outs in the history of the main international competitions for national teams and for club teams, as well as data on various national club competitions. Table 1 provides a summary of the dataset.

For every shoot-out of every competition we have information on the date, the identity of the teams kicking first and second, the final outcome, the outcomes of each of the kicks in the sequence (with the exception of one shoot-out), and the geographical location of the game (that is, whether the game was played at a home ground, a visiting ground, or in a neutral field).

As is well known, and following the description in Manski (1995), let $y_{z}$ be the outcome that a subject (a team in our case) would realize if he were to receive treatment $z$, where $z=0,1$. Let $P\left(y_{z} \mid x\right)$ denote the distribution of outcomes that would be realized if all subjects with covariates $x$ were to receive treatment $z$. The objective is to compare the distributions $P\left(y_{1} \mid x\right)$ and $P\left(y_{0} \mid x\right)$. When the treatment $z$ received by each subject with covariates $x$ is statistically independent of the subject's outcomes, we have $P\left(y_{z} \mid x\right)=P\left(y_{z} \mid x, z=1\right)=P\left(y_{z} \mid x, z=0\right)$ for $z=0,1$. Now let $y \equiv y_{1} z+y_{0}(1-z)$ denote the outcome actually realized by a member of the population, namely, $y_{1}$ when $z=1$ and $y_{0}$ when $z=0$. Note that $P(y \mid x, z=1)=P\left(y_{1} \mid x, z=1\right)$ and $P(y \mid x, z=0)$ $=P\left(y_{0} \mid x, z=0\right)$. Hence, if we denote by $B$ the set of outcome values (that is, win or lose in our 
Table 2-Pretreatment Characteristics

\begin{tabular}{lcccc}
\hline \hline Criterion & $N$ & First team & Second team & Difference \\
\hline FIFA rankings & 35 & 0.46 & 0.54 & -0.08 \\
& & $(0.50)$ & $(0.50)$ & $(1.01)$ \\
UEFA rankings & 20 & 0.35 & 0.65 & -0.30 \\
& & $(0.49)$ & $(0.49)$ & $(0.99)$ \\
Category & 58 & 0.50 & 0.50 & 0.00 \\
& & $(0.35)$ & $(0.35)$ & $(0.70)$ \\
Position & 30 & 0.4 & 0.6 & -0.20 \\
$\quad$ (when same category) & \multirow{2}{*}{128} & $(0.50)$ & $(0.50)$ & $(0.996)$ \\
Experience & & 0.48 & 0.52 & -0.03 \\
& & $(0.32)$ & $(0.32)$ & $(0.65)$ \\
Home team & 82 & 0.57 & 0.43 & 0.14 \\
\hline
\end{tabular}

Notes: FIFA publishes ranks on national teams since 1993. The UEFA ranking applies to international club team competitions (Champions League and UEFA Cup), and it is published since 1959. Teams taking part in national cup competitions-Spanish Cup, German Cups, and English Cups-may or may not belong to the same category (division) in the national league competition. If they belong to the same one, we consider their standings ("Position") in the league table at the time of the shoot-out. Experience refers to the number of previous shootouts in which a team has participated in which we observe in our dataset. The table reports the proportion of times in which each team shows a better entry in the respective criterion $(=1$ if higher, $=0$ if lower, $=0.5$ if same). Home team equals 1 if the team plays in its own stadium. Standard deviations in parentheses.

case), when the treatment is independent of the outcomes, the estimate of the average treatment effect $T(B \mid x)$ is:

$$
T(B \mid x)=P(y \in B \mid x, z=1)-P(y \in B \mid x, z=0) .
$$

Next, we first confirm the statistical similarity of the pretreatment characteristics of the two teams involved in a shoot-out. The main covariates we are interested in are variables that measure the quality of the teams, their previous experience in shoot-outs, and environmental factors such as the nature of the crowd in the stadium, since these may represent differences in support or pressure experienced by the teams. With respect to the quality of the teams, FIFA and UEFA publish yearly rankings both for national teams and clubs based on their performance in certain competitions. For the national team competitions we use the "FIFA rankings," and for international club competitions the "UEFA team rankings." 12 For club competitions at the national level we consider the division or category to which the teams belong at the time of the shoot-out and, when they belong to the same division, their standings in the table. With respect to experience, we compute the number of previous shoot-outs observed in our dataset in which a given team has been involved. Lastly, we consider whether a team is playing at its own stadium in front of mostly a supporting home crowd, at the stadium of its opponent in front of a predominantly unfriendly crowd, or at a neutral venue. Table 2 reports the differences in these characteristics.

Consistent with the randomization procedure used to determine the order of play, it is not possible to reject the null hypothesis of equality in any of these covariates at conventional significance levels.

We now turn to the main result of this paper. As indicated earlier, the estimate of the average treatment effect is $P(y \in B \mid x, z=1)-P(y \in B \mid x, z=0)$. We compute this effect and find

\footnotetext{
${ }^{12}$ The methodology used to construct these rankings is described at http://www.fifa.com and http://www.uefa.com.
} 
that teams kicking first in the sequence win the penalty shoot-out 60.5 percent of the time (see Figure 1). That is, kicking first conveys a strongly significant (at the 1.7 percent level) and sizable advantage. For the complete dataset (1970-2008) the effect is 59.2 percent, significant at the 0.5 percent level.

In Table 3 we use a regression framework to provide an estimate of the treatment effect using various probit and logit specifications.

We find, not surprisingly, that the order of play is strongly significant in every specification. In fact, when we control for all the observed covariates $\chi$ in the regressions the significance of the effect increases more than tenfold. Furthermore, it is also interesting to note that none of the covariates included in the regressions is significant in any of the specifications. These results confirm the significant and sizable advantage gained by the team that is first to kick.

\section{Discussion}

\section{A. Are Professionals Aware of Any Psychological Effects on Performance?}

As indicated earlier, in July 2003 FIFA introduced a slight change in the procedure used to determine the kicking order. Rather than requiring that the winner of the coin toss must take first kick, it required that he chooses whether to take the first kick or the second kick. This change allows us to study the response of professionals to the psychological phenomenon we have documented:

(i) Professionals may or may not be aware of it;

(ii) If they are, they may or may not react optimally to it;

(iii) And if they do react optimally, they may or may not do so for the right reason.

Clearly, if subjects are aware of any psychological effects caused by the order of play and their detrimental impact on performance, they should always choose to go first in the tournament. Unfortunately, there are no public records of players' choices because FIFA regulations do not require referees to record this information..$^{13}$ In order to get to know what their choices after July 2003 are, we have done the following:

1. First, we watched about twenty videos of matches that ended in a penalty shoot-out. Although the interval between the end of a game and the beginning of a shoot-out is typically used by TV channels to air commercials, it is sometimes possible to catch the very instant when the referee flips the coin and talks to the winner of the toss. We found that in each and every case that we were able to observe with just one exception, the winner of the coin toss chose to kick first. ${ }^{14}$

2. Second, we conducted a survey of more than 240 players and coaches in the professional and amateur leagues in Spain, who were asked the following question: "Assume you are playing a penalty shoot-out. You win the coin toss and have to choose whether to kick

\footnotetext{
${ }^{13}$ See the complete regulations at http://www.fifa.com.

${ }^{14}$ The exception is the Italy-Spain match in the quarter finals of the European Championship, June 2008. Gianluigi Buffon, the Italian goalkeeper, won the toss and chose Spain to kick first. Spain won.
} 


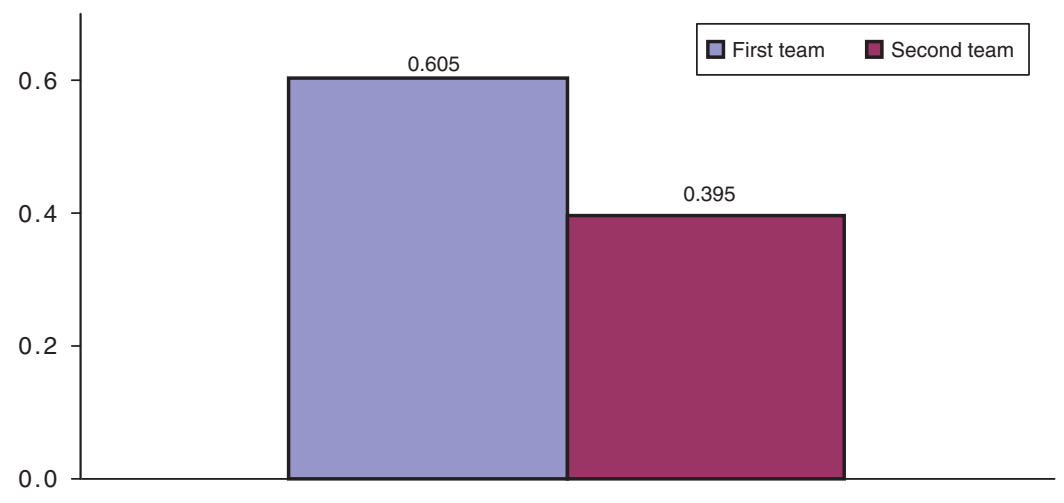

Figure 1. Winning Frequencies in Aggregate Data

Table 3-Determinants of Winning the Tournament

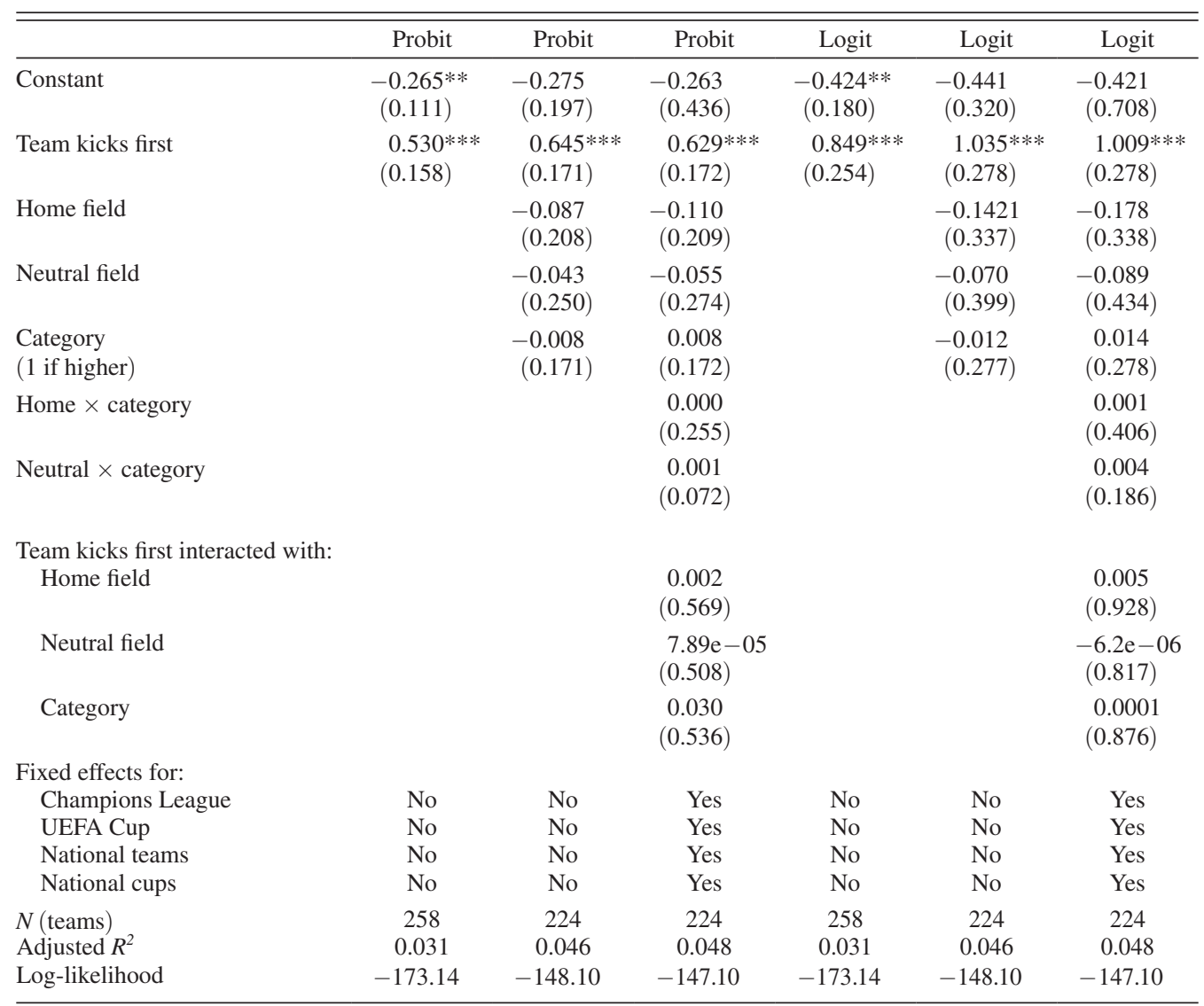

Notes: Missing observations for "Category" for 17 shoot-outs. Standard errors in parentheses. $* * *$ Significant at the 1 percent level.

**Significant at the 5 percent level. 
TABle 4-Survey Results

\begin{tabular}{|c|c|c|c|c|c|}
\hline \multicolumn{6}{|c|}{$\begin{array}{l}\text { The following questions were asked to soccer coaches and players: } \\
\text { Q1: "Assume you are playing a penalty shoot-out. You win the coin toss and have to } \\
\text { choose whether to kick first or second. What would you choose: first; second; either } \\
\text { one, I am indifferent; or, it depends?" }\end{array}$} \\
\hline & Observations & First & Second & Indifferent & Depends \\
\hline $\begin{array}{l}\text { Coaches: } \\
\text { Professional } \\
\text { Amateur }\end{array}$ & $\begin{array}{l}21 \\
37\end{array}$ & $\begin{array}{l}90.5 \% \\
94.6 \%\end{array}$ & $\begin{array}{l}0 \\
0\end{array}$ & $\begin{array}{l}0 \\
0\end{array}$ & $\begin{array}{l}9.5 \% \\
5.4 \%\end{array}$ \\
\hline $\begin{array}{l}\text { Players: } \\
\text { Professional } \\
\text { Amateur }\end{array}$ & $\begin{array}{r}67 \\
117\end{array}$ & $\begin{array}{l}97.0 \% \\
96.5 \%\end{array}$ & $\begin{array}{l}0 \\
0\end{array}$ & $\begin{array}{l}1.5 \% \\
2.5 \%\end{array}$ & $\begin{array}{l}1.5 \% \\
1.0 \%\end{array}$ \\
\hline $\begin{array}{l}\text { All: } \\
\text { Q2: "F }\end{array}$ & $\begin{array}{c}242 \\
\text { ase explain you }\end{array}$ & $\begin{array}{l}95.9 \% \\
\text { lecision. }\end{array}$ & $\begin{array}{c}0 \\
\text { would yo }\end{array}$ & $\begin{array}{c}1.6 \% \\
\text { what you jus }\end{array}$ & $\begin{array}{l}2.5 \% \\
\text { iid?" }\end{array}$ \\
\hline
\end{tabular}

first or second. What would you choose: first; second; either one, I am indifferent; or, it depends?" The results are collected in Table 4.

We found that around 96 percent of the subjects answered that they would prefer to go first. More importantly, when asked to explain their decision, they systematically argued that their choice was motivated by the desire to put pressure on the kicker of the opposing team. Coding their answers to a second question we asked in the survey: "Please explain your decision: why would you do what you just said?," we find that in 96 percent of the cases they explicitly mention that they intend to put pressure on the kicker of the second-kicking team, and that in no case do they refer to the possibility of enhancing the performance of their own goalkeeper.

We interpret this evidence as supporting the hypothesis that subjects are perfectly aware of the result and, more important, they respond optimally to it. This means, following the terminology used in behavioral economic theory, that they can be characterized as "sophisticates." Further, they attribute the result to a specific psychological mechanism that leads to pressure and underperformance. In the next subsections we study whether this is also substantiated in the data.

\section{B. Descriptive Evidence of Dynamic Performance}

Table 5 reports round by round data of winning frequencies for each team. As indicated earlier, when the shoot-out remains tied after five rounds kicks continue to be taken in the same order in additional rounds until one team has scored a goal more than the other from the same number of kicks. We will call these "decisive rounds."

We find that most of the shoot-outs (about three-quarters) end in five or fewer rounds, and the rest move into decisive rounds. The team kicking first wins 65.9 percent of all the shoot-outs that end in five rounds or less, and 52.9 percent of the rest. The lower advantage in the decisive rounds may simply reflect a selection effect, namely that it involves first teams that have failed to capitalize on the advantage of kicking first during five rounds or more.

Figures $2 \mathrm{~A}$ and $2 \mathrm{~B}$ report the unconditional scoring rates per round for the first five rounds, and the unconditional frequencies with which a given team (first or second) is ahead of its opponent in the score at the end of each of these rounds. 
TABle 5-Observations by Round and Winning Rates

\begin{tabular}{|c|c|c|c|c|}
\hline \multirow[b]{2}{*}{ Round } & \multicolumn{2}{|c|}{ Number of shoot-outs } & \multicolumn{2}{|c|}{ If decided, percentage in which the: } \\
\hline & Observed & Decided & First team wins & Second team wins \\
\hline \multicolumn{5}{|c|}{ Regular rounds } \\
\hline Round 1 & 128 & 0 & - & - \\
\hline Round 2 & 128 & 0 & - & - \\
\hline Round 3 & 128 & 1 & 100 & 0 \\
\hline Round 4 & 127 & 30 & 76.6 & 23.3 \\
\hline \multirow[t]{2}{*}{ Round 5} & 97 & 63 & 60.3 & 39.7 \\
\hline & Total decided: & 94 & 65.9 & 34.1 \\
\hline \multicolumn{5}{|c|}{ Decisive rounds } \\
\hline Round 6 & 34 & 18 & 38.8 & 61.2 \\
\hline Round 7 & 16 & 4 & 75.0 & 25.0 \\
\hline Round 8 & 12 & 5 & 80.0 & 20.0 \\
\hline Round 9 & 7 & 1 & 0 & 100 \\
\hline Round 10 & 6 & 3 & 100 & 0 \\
\hline Round 11 & 3 & 1 & 0 & 100 \\
\hline \multirow[t]{2}{*}{ Round 12} & 2 & 2 & 50.0 & 50.0 \\
\hline & Total decided: & 34 & 52.9 & 47.1 \\
\hline All rounds & Total decided: & 128 & 60.2 & 39.5 \\
\hline
\end{tabular}

Note: We are missing the round by round data of one shoot-out which was won by the first team in five rounds.

The scoring rate in the aggregate data is 73.1 percent, 76.3 percent for the first team and 69.7 percent for the second. ${ }^{15}$ Figure $2 \mathrm{~A}$ shows that it is always greater for the first team than for the second team and appears to decline in the later rounds. Figure $2 \mathrm{~B}$ shows that the differences in scoring rates tend to make the first team more likely to be leading in the score than the second team at the end of every round. The difference between the teams is 7 percentage points in each of the first two rounds, which is not significant at conventional levels, and increases in magnitude in subsequent rounds to 12,13 , and 19 percentage points respectively, becoming statistically significant (at the 1 percent level). Interestingly, the relative frequency with which the first team leads in the partial score when one of the two teams is leading is around 60 percent, increasing slightly in the later rounds. These findings suggest that the detrimental effects on performance become more pronounced as the potential final rounds are approached.

Table 6 provides a more detailed description of both scoring probabilities and winning frequencies by team, round, and partial score.

Not surprisingly, most of the observations for the first team occur when the partial score is tied, and for the second team when it is lagging in the score. The scoring rate along these two paths of observations (columns 2 and 4) is nearly always higher for the first team than for the second. It also appears to drop over the rounds quite significantly for the second team but not for the first: for the second team it falls from about 75-80 percent in the first two rounds to about 62-66 percent in rounds 3 to 5, whereas for the first team it remains fairly stable in a range of 72-78 percent. The percentage of times with which the teams observed at every round-score combination eventually

\footnotetext{
${ }^{15}$ These rates are lower than the average scoring rate in penalty kicks in the normal course of a game (that is, not in shoot-outs), which is about 80 percent, but similar to the scoring rate in games with a close score (a tie or a one goal difference) when there is little time left to play in the game (see, e.g., Palacios-Huerta 2003). These lower rates may reflect the increased pressure associated with the fact that scoring a goal or not is a critical determinant of the final outcome both in a penalty shoot-out and in close games.
} 


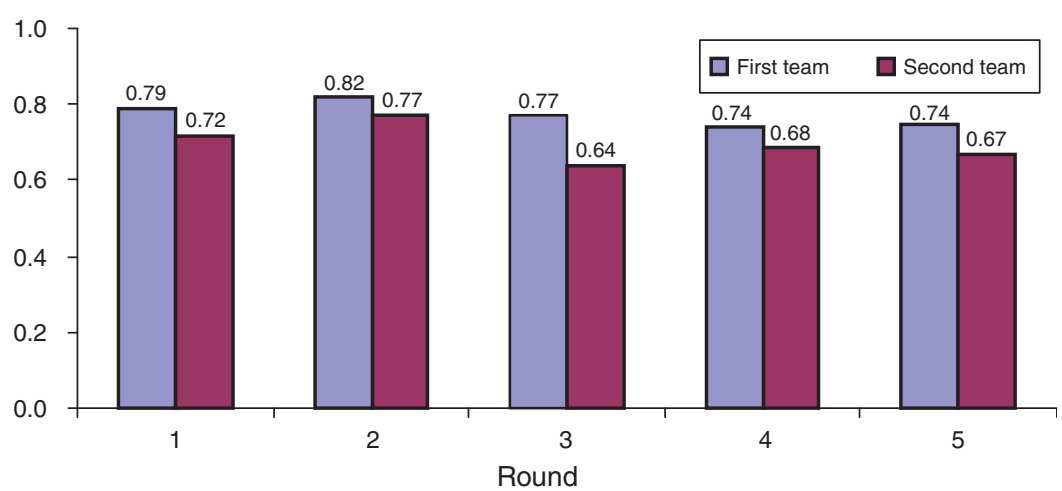

Figure 2A. SCORING Probabilities Per Round

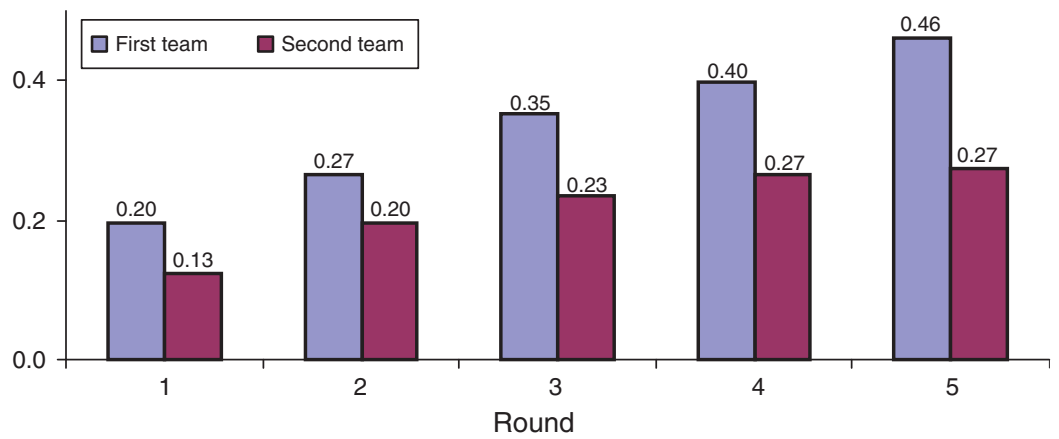

Figure 2B. Frequency with which a Team Leads in the Score at the End of a Round

Notes: If before both teams have taken five penalty kicks, one has score more goals than the other could possibly score even if it were to complete its five kicks, no more kicks are taken. The percentage of times in which a team is leading in the score at the end of a round in Figure $2 \mathrm{~B}$ includes these cases, that is, cases in which the shoot-out already ended before this round, whereas in Figure $2 \mathrm{~A}$ the scoring rate is only computed for the teams that are observed to kick in the corresponding round.

win the shoot-out reveals that the impact of scoring versus not scoring increases over the rounds for both teams. In round 1, for instance, the first team begins with a 60.2 percent chance of winning. If it scores, this probability increases 7.1 percentage points (to $67.3=100-32.7$ ) and if it misses the probability drops 26.9 percentage points (to $33.3=100-66.7$ ). The corresponding figures for round 5 are +17.6 and -35.7 percentage points, respectively. Thus, the cumulative impact of any scoring rate differentials over five rounds can be substantial. One way to capture the "importance" of a penalty kick is to compute the difference in these conditional probabilities relative to the ex ante probability of winning the shoot-out at that state. For instance, for the first team in round 1, the "Penalty Kick Importance" is simply $(67.3-33.3) / 60.2=56.5$. It turns out that there is a slightly negative but insignificant correlation $\rho$ between the importance of a penalty kick and the scoring rate $(\rho=-0.008, p$-value $=0.96)$. Interestingly, however, the data also show that along the two most frequent paths of observations (columns 2 and 4) in nearly all the cases the importance is substantially greater for the second team than for the first team. The correlation between importance and performance just within this subset of observations is $\rho=-0.557, p$-value $=0.06$.

Taken together, while the descriptive evidence just presented is at most suggestive of the mechanism that may generate the phenomenon we study, it shows substantial differences between the two 
Table 6-Scoring Probabilities and Winning Frequencies by Team, Round, and Partial Score

\begin{tabular}{|c|c|c|c|c|c|c|}
\hline & \multicolumn{3}{|c|}{ First team } & \multicolumn{3}{|c|}{ Second team } \\
\hline & Behind & Even & Ahead & Behind & Even & Ahead \\
\hline \multicolumn{7}{|l|}{ Round 1} \\
\hline Scoring probability & - & 78.9 & - & 75.2 & 59.3 & - \\
\hline Percent win shoot-out & - & 60.2 & - & 32.7 & 66.7 & - \\
\hline Penalty kick importance & & 56.5 & & 93.4 & 39.3 & \\
\hline$N$ & - & 128 & - & 101 & 27 & - \\
\hline \multicolumn{7}{|l|}{ Round 2} \\
\hline Scoring probability & 100 & 74.7 & 96.0 & 82.2 & 65.8 & - \\
\hline Percent win shoot-out & 31.3 & 57.5 & 88.0 & 32.2 & 57.9 & - \\
\hline Penalty kick importance & - & 32.2 & 30.6 & 62.7 & 61.2 & \\
\hline$N$ & 16 & 87 & 25 & 90 & 38 & 0 \\
\hline \multicolumn{7}{|l|}{ Round 3} \\
\hline Scoring probability & 80.0 & 76.8 & 76.5 & 63.2 & 69.4 & 40.0 \\
\hline Percent win shoot-out & 24.0 & 59.4 & 88.2 & 23 & 72.2 & 100 \\
\hline Penalty kick importance & 115.7 & 67.3 & 21.9 & 62.7 & 66.4 & 14.3 \\
\hline$N$ & 25 & 69 & 34 & 87 & 36 & 5 \\
\hline \multicolumn{7}{|l|}{ Round 4} \\
\hline Scoring probability & 76.7 & 71.7 & 75.0 & 66.2 & 69.4 & 77.8 \\
\hline Percent win shoot-out & 13.3 & 62.3 & 88.6 & 21.1 & 75.0 & 100 \\
\hline Penalty kick importance & 150.0 & 68.2 & 19.8 & 125.1 & 50.1 & 14.8 \\
\hline$N$ & 30 & 53 & 44 & 71 & 36 & 9 \\
\hline \multicolumn{7}{|l|}{ Round 5} \\
\hline Scoring probability & 74.1 & 76.2 & 71.4 & 62.5 & 70.0 & - \\
\hline Percent win shoot-out & 14.8 & 52.4 & 96.4 & 30.0 & 83.3 & - \\
\hline Penalty kick importance & 112.5 & 101.8 & 31.1 & 156.9 & 63.5 & \\
\hline$N$ & 27 & 42 & 28 & 40 & 30 & - \\
\hline \multicolumn{7}{|l|}{ Rounds $6+$} \\
\hline Scoring probability & - & 67.5 & - & 68.5 & 65.4 & - \\
\hline Percent win shoot-out & - & 58.8 & - & 24.1 & 76.9 & - \\
\hline Penalty kick importance & & 90.0 & & 153.5 & 84.7 & \\
\hline$N$ & - & 80 & - & 54 & 26 & - \\
\hline
\end{tabular}

Notes: For each team-score-round situation, the "Scoring probability" is the percentage of teams that scored a goal in that situation, "Percent win shoot-out" is the percentage of teams observed in that situation that eventually won the shootout, and "Penalty kick importance" is the probability of winning the shoot-out when the penalty kick is scored minus the probability when it is not scored divided by the probability of winning the shoot-out (that is, by "Percent win shootout"). $N$ is the number of observations. In Rounds $6+N$ is computed as the sum of the number of teams that in rounds 6 and beyond are observed at a given partial score. That is, since the first team can be observed in various rounds with an even partial score and the second team can be observed in various rounds with the same or different (behind and even) score, the same team may be observed at multiple occasions. The scoring probabilities and the percentage of teams that win the shoot-out are computed using these as the number of observations for these rounds. We are missing the round by round data in one shoot-out.

teams: the second team has a lower scoring rate, especially in the later rounds, and typically finds itself kicking penalty kicks which have greater importance in terms of changes in probabilistic outcomes. In the next subsection we provide a more rigorous analysis of the dynamics of the tournament.

\section{Dynamic Panel Data Analysis}

The outcome of a penalty kick (score, no score) in a shoot-out may depend on certain observed and unobserved characteristics of the teams and the penalty shoot-out, the specific sequence of past outcomes and the state of the tournament shoot-out. Not having a random assignment of any of these variables, we estimate a binary choice panel data model with lagged endogenous variables and unobserved heterogeneity. In particular, in order to appropriately control for the effect 
Table 7-Random Effects Dynamic Panel Data Model

\begin{tabular}{|c|c|c|c|}
\hline & (1) & $(2)$ & (3) \\
\hline Constant & $\begin{array}{l}0.95 * * * \\
(6.77)\end{array}$ & $\begin{array}{l}0.87 * * * \\
(3.03)\end{array}$ & $\begin{array}{l}0.82 * * * \\
(2.92)\end{array}$ \\
\hline Lagged penalty outcome & $\begin{array}{c}-0.27 \\
(1.02)\end{array}$ & $\begin{array}{c}-0.25 \\
(1.12)\end{array}$ & $\begin{array}{c}0.10 \\
(0.93)\end{array}$ \\
\hline Partial score +1 & $\begin{array}{c}0.98 \\
(1.23)\end{array}$ & $\begin{array}{c}0.67 \\
(0.50)\end{array}$ & $\begin{array}{l}1.77 \\
(0.82)\end{array}$ \\
\hline Partial score 0 & $\begin{array}{c}2.34 \\
(0.45)\end{array}$ & $\begin{array}{c}1.44 \\
(0.53)\end{array}$ & $\begin{array}{c}1.25 \\
(0.45)\end{array}$ \\
\hline Partial score -1 & $\begin{array}{l}-0.21 * * * \\
(5.21)\end{array}$ & $\begin{array}{l}-0.17 * * * \\
(3.18)\end{array}$ & $\begin{array}{l}-0.14 * * * \\
(3.19)\end{array}$ \\
\hline Second team & & $\begin{array}{l}-0.04 * * \\
(1.70)\end{array}$ & $\begin{array}{c}-0.02 \\
(1.60)\end{array}$ \\
\hline Partial score $-1 \times$ second team & & $\begin{array}{l}0.02^{* *} \\
(1.65)\end{array}$ & $\begin{array}{l}0.02 * * \\
(1.68)\end{array}$ \\
\hline Penalty kick importance & & $\begin{array}{c}-0.23 \\
(1.10)\end{array}$ & $\begin{array}{c}-0.09 \\
(1.18)\end{array}$ \\
\hline Potential winner penalty kick & & $\begin{array}{c}-0.94 \\
(1.03)\end{array}$ & $\begin{array}{c}-0.03 \\
(1.09)\end{array}$ \\
\hline Potential loser penalty kick & & $\begin{array}{c}-0.88 \\
(1.05)\end{array}$ & $\begin{array}{c}-0.53 \\
(1.20)\end{array}$ \\
\hline International competition & $\begin{array}{c}-0.03 \\
(0.38)\end{array}$ & $\begin{array}{c}0.44 \\
(0.27)\end{array}$ & $\begin{array}{c}-0.01 \\
(0.32)\end{array}$ \\
\hline Final match & $\begin{array}{r}-1.20 \\
(0.99)\end{array}$ & $\begin{array}{c}-0.05^{*} \\
(1.32)\end{array}$ & $\begin{array}{l}-0.06 \\
(1.07)\end{array}$ \\
\hline Semifinal match & $\begin{array}{c}-0.23 \\
(0.19)\end{array}$ & $\begin{array}{r}-0.33 \\
(0.09)\end{array}$ & $\begin{array}{c}-0.42 \\
(0.08)\end{array}$ \\
\hline Field fixed effects & Yes & Yes & Yes \\
\hline Round fixed effects & Yes & Yes & Yes \\
\hline Goalkeeper fixed effects & No & No & Yes \\
\hline Competition type fixed effects & No & No & Yes \\
\hline
\end{tabular}

Notes: The endogenous variable equals 1 if the penalty is scored and 0 otherwise. "Partial score $\mathrm{X}$ " are dummy variables for penalties where the score from the perspective of the kicking team is $\mathrm{X}$ at the time of kicking. "Potential winner penalty kick" and "Potential loser penalty kick" are dummy variables for penalty kicks which if scored or missed mean that the shoot-out will be won or lost respectively. Field fixed effects refer to home field, neutral field, or opponent's home team field. The sample has 1,343 individual penalty kick observations. Absolute, choicebiased sampling, heteroskedastic-consistent $t$-statistics are reported in parentheses. The model is estimated by GMM.

*** Significant at the 1 percent level.

** Significant at the 5 percent level.

* Significant at the 10 percent level.

of state dependence in our setting, we estimate the semi-parametric dynamic random effects panel data model of Manuel Arellano and Raquel Carrasco (2003). These authors develop a consistent random effects estimator where: (a) explanatory variables are predetermined but not strictly exogenous, and where (b) individual effects are allowed to be correlated with the explanatory variables. In online Appendix A we describe this method, discuss its advantages over the alternatives available in the literature, and show how our short panel fits its identification requirements. ${ }^{16}$ The results are collected in Table 7.

\footnotetext{
${ }^{16}$ The econometric estimation of these models is typically subject to a number of difficulties. For example, parameter estimates from short panels jointly estimated with individual fixed effects can be seriously biased and inconsistent. See Arellano and Bo Honoré (2001) for a review.
} 
TABle 8-Marginal EFFects

\begin{tabular}{|c|c|c|c|c|c|c|}
\hline & Round 1 & Round 2 & Round 3 & Round 4 & Round 5 & Round 6+ \\
\hline \multicolumn{7}{|c|}{ Panel A. Partial score } \\
\hline \multicolumn{7}{|c|}{ From 0 to 1 : } \\
\hline First team & - & 1.46 & 1.63 & 1.41 & 3.74 & - \\
\hline Second team & - & 2.35 & 2.50 & 3.55 & - & - \\
\hline \multicolumn{7}{|l|}{ From 0 to -1 : } \\
\hline First team & - & -1.73 & -2.17 & -3.85 & -5.82 & - \\
\hline Second team & -3.12 & -0.39 & -1.42 & -2.35 & -4.46 & -6.88 \\
\hline \multicolumn{7}{|c|}{ Panel B. Kicking first instead of kicking second } \\
\hline & 0.26 & 0.35 & 0.57 & 1.05 & 1.37 & 2.53 \\
\hline
\end{tabular}

We find that the main determinant of the scoring rate is whether the team is lagging in the score: the variable "partial score -1 " has a negative effect that is strongly significant at conventional levels, regardless of whether other endogenous variables relating to the state of the shoot-out are included or not. This means that lagging in the score hinders the performance of the subjects. Consequently, the team more likely to find itself with a partial score of -1 (by construction, the second kicking team) will have significantly greater chances of losing the tournament. We also find that this effect is mitigated if the kicking team is the one kicking in second place. This latter result is consistent with the intuition that, while a negative partial score is bad news, it is especially bad news for a team that has had exactly the same opportunities to score as its opponent (the first team to kick). With respect to the magnitude of the effects, Table 8 reports the marginal effects associated with different partial scores and different rounds.

The results in panel A show that the transition of a team from a partial score of 0 to +1 has a positive impact. For the team kicking first, the increase in the probability of scoring is around 1.50 percent per round for rounds 2 to 4 , reaching 3.74 percent in the fifth round. The impact is, as expected, greater for the second team, and ranges from 2.35 percent to 3.55 percent for rounds 2 to 4 . Moving a team from a partial score of 0 to -1 has a negative impact, whose magnitude in absolute value is greater for the team kicking first and lower for the team kicking second at any given round than in the case when we move a team from 0 to +1 . Finally, since we are dealing with a two-agent zero-sum game, these marginal effects must be compounded in a zero-sum fashion (when one team goes from 0 to +1 , the other team must go from 0 to -1 ) to gain a sense of their impact on a team's chances of winning the tournament. Consistent with the basic intuition from the raw data, this compounded effect is greater in rounds 4 and 5 than in the earlier rounds. For the decisive rounds, the marginal effect for the second team (the only one that exists in these rounds) is 6.98 percent. This effect is sizable, although somewhat smaller than the compound effect in round 5.

In panel B the marginal effects of kicking first rather than second net of other effects are positive, though small in magnitude, ranging from 0.26 to 1.37 percent for the first five rounds, and rising to 2.53 percent in the decisive rounds.

Finally, it is important to remark that a penalty kick involves two players: a kicker and a goalkeeper. Hence, it is theoretically possible to consider that it is not that the kicker's performance is hindered by a negative partial score, but rather that the goalkeeper's performance is enhanced 
when his team's partial score is positive. Although this is theoretically possible, in the survey presented earlier professional players systematically report that the effect is to put psychological pressure on the kicker. Not a single player mentions the possibility that the performance of the first team's goalkeeper may be enhanced when the partial score is in his favor. In addition, for a subset of all the penalty shoot-outs in the sample we have detailed information on whether the no-goals are due to "saves" by the goalkeeper or "misses" by the kicker. In online Appendix A we report the basic features of this subset of the data and the results of a multinomial logit specification with goals, misses, and saves. The raw data show that both teams have basically the same proportion of saves, and hence that the difference in scoring rates between the first and the second team basically corresponds to their difference in misses. The logit regressions then show that lagging in the score predicts more misses by the kicker but predicts no more saves by the goalkeeper. Hence, these results are also consistent with the idea that the psychological effects may operate mainly through the kicker. ${ }^{17}$

\section{Policy Implications}

We have found that in a dynamic competitive setting, when information on the performance of the competing agents is available or released in the interim periods or stages, the state of competition may have an impact on performance. Thus, these results highlight the role of performance information in competitive settings and also show that, in terms of the theory of optimal incentive provision, the timing of tasks can be important exclusively for psychological reasons: even when the order of the tasks is determined through a perfect randomized trial, the outcome can be ex post unfair. One way to accomplish an ex post fair outcome would be to require that the agents perform their task simultaneously. Another would be to require that interim performance be only privately observed and not publicly. In our specific setting it may even be optimal to require that agents perform their task before the game starts. ${ }^{18}$ In more general settings where other factors such as the choice of effort levels and risky strategies may play a role, it is entirely an empirical question how the psychological effects we have documented interact with decision-making processes and how they then jointly determine performance. 19 Hence, the results have implications for the merits of different incentive schemes and for the choice of performance information revelation rules. For instance, school officials can decide whether or not to reveal the scores of the students in each round of a contest; in political competitions, election commissions may design specific policies about the release of information regarding voting tendencies before the date of the election, and in competitions for promotion in internal labor markets principals may

\footnotetext{
${ }^{17}$ When kickers miss the goal, the goalkeeper's performance is irrelevant, and so he may perform worse (or better) under pressure. Since most penalties are scored, the upside for the goalkeeper is always greater but less likely than the downside. The opposite is the case for the kicker: his upside is smaller but more likely than the downside. Hence, a greater pressure on the kicker may be explained in terms of some form of probabilistic loss aversion, that is if losses are perceived disproportionally larger than gains. We are indebted to a referee for these suggestions.

${ }^{18}$ We are indebted to a referee for this suggestion. Juan D. Carrillo (2007) shows that the timing of the shoot-out may affect the incentives to exert and allocate effort in the game, and that the attractiveness (appropriately defined) of the game could increase if the shoot-out would take place before rather than after the match is over. Although it is a priori unclear in which direction and to what extent the order of events might affect strategies, effort levels, and final outcomes, it is theoretically possible that changing the timing of the shoot-out might induce the winning and losing teams to adopt strategies that will make the shoot-out ex post fair.

${ }^{19}$ Intuitively, subjects treated unfairly by the random draw of order would tend to fall behind and then react by exerting more effort and/or taking more risks than they would otherwise for precisely the same reasons as in the literature cited earlier (see footnote 2).
} 
decide whether or not to reveal their (partial) assessment of the performance of workers before the competition is over. 20

\section{Concluding Remarks}

Nature seldom creates circumstances that allow a transparent view of psychological elements at work. And, when it does, the phenomena are typically too complex to clearly discern the impact of these elements on human behavior. The randomized experiment we have studied provides an unusual opportunity and involves highly incentivized professionals performing a simple, familiar task, in a real world strictly competitive situation.

The results provide support for a source of psychological pressure that has a detrimental effect on performance, and that is different from others such as high stakes, social pressure or peer pressure previously documented in the literature. Since this is a source that is endogenous to the course of the competition, the results are relevant from both a theoretical and an empirical perspective for competitive environments at large. In particular, R\&D races, political elections, competitions for promotion within certain firms and organizations, student competitions in schools and others represent competitive settings that share some or all of the main characteristics of the setting we have studied: they are strictly competitive (zero-sum) situations and feedback information on performance and the state of competition is available to the participants during the competition. Whether or not psychological elements are important, or even critical, is entirely an empirical question. What the results in this paper indicate is that they are critical in the setting that we have studied, and hence that future theoretical and empirical research on dynamic competitive settings that incorporate psychological elements associated with the state of the competition may offer insights that otherwise would be lost.

Lastly, from the perspective of the recent behavioral economics literature, we find a significant and quantitatively important type of psychological effect not previously documented. From the perspective of rational choice theory, we find that individuals are aware of this effect and they rationally respond to it.

\section{REFERENCES}

Arellano, Manuel, and Raquel Carrasco. 2003. "Binary Choice Panel Data Models with Predetermined Variables." Journal of Econometrics, 115(1): 125-57.

Arellano, Manuel, and Bo Honoré. 2001. "Panel Data Models: Some Recent Developments." in Vol. 5, Handbook of Econometrics, ed. James Heckman and Edward Leamer, 3229-96. Amsterdam: NorthHolland.

-Ariely, Dan, Uri Gneezy, George Loewenstein, and Nina Mazar. 2009. "Large Stakes and Big Mistakes." Review of Economic Studies, 76(2): 451-69.

Becker, Gary S. 1976. The Economic Approach to Human Behavior. Chicago: University of Chicago Press.

Becker, Gary S. 1996. Accounting for Tastes. Cambridge, MA: Harvard University Press.

Becker, Gary S., and Kevin M. Murphy. 2000. Social Economics: Market Behavior in a Social Environment. Cambridge, MA: Harvard University Press.

Beilock, Sian. 2007. “Choking Under Pressure.” In Encyclopedia of Social Psychology, ed. Roy F. Baumeister, and Kathleen D. Vohs, 140-41. Thousand Oaks, CA: Sage Publications.

- Bhaskar, V. 2009. "Rational Adversaries? Evidence from Randomised Trials in One Day Cricket." Economic Journal, 119(534): 1-23.

-Cabral, Luis M. B. 2002. "Increasing Dominance with No Efficiency Effect." Journal of Economic Theory, 102(2): 471-79.

\footnotetext{
${ }^{20}$ In online Appendix B we provide a simple theoretical model that is consistent with the evidence we have presented. The model can be easily generalized to more general settings and is also useful to study specific policy implications for penalty shoot-outs such as the optimal allocation of players when they are heterogeneous in quality.
} 
Cabral, Luis M. B. 2003. "R \& D Competition When Firms Choose Variance." Journal of Economics and Management Strategy, 12(1): 139-50.

-Caplin, Andrew, and John Leahy. 2001. "Psychological Expected Utility Theory and Anticipatory Feelings." Quarterly Journal of Economics, 116(1): 55-79.

-Carrillo, Juan D. 2007. "Penalty Shoot-Outs: Before or after Extra Time?" Journal of Sports Economics, $8(5): 505-18$.

Che, Yeon-Koo, and Terrence Hendershott. 2008. "How to Divide the Possession of a Football?" Economics Letters, 99(3): 561-65.

DellaVigna, Stefano. 2009. "Psychology and Economics: Evidence from the Field." Journal of Economic Literature, 47(2): 315-72.

Epstein, Larry G., and Igor Kopylov. 2007. “Cold Feet.” Theoretical Economics, 2(3): 231-59.

Ericsson, K. Anders, Neil Charness, Robert R. Hoffman, and Paul J. Feltovich, ed. 2006. The Cambridge Handbook of Expertise and Expert Performance. Cambridge, UK: Cambridge University Press.

Hvide, Hans K. 2002. "Tournament Rewards and Risk Taking." Journal of Labor Economics, 20(4): 877-98.

-Hvide, Hans K., and Eirik G. Kristiansen. 2003. "Risk Taking in Selection Contests." Games and Economic Behavior, 42(1): 172-79.

Kahneman, Daniel. 1973. Attention and Effort. Englewood Cliffs, NJ: Prentice Hall.

-Köszegi, Botond, and Matthew Rabin. 2006. "A Model of Reference-Dependent Preferences." Quarterly Journal of Economics, 121(4): 1133-65.

- Lazear, Edward P., and Sherwin Rosen. 1981. "Rank-Order Tournaments as Optimum Labor Contracts." Journal of Political Economy, 89(5): 841-64.

-Loewenstein, George. 1987. "Anticipation and the Valuation of Delayed Consumption." Economic Journal, 97(387): 666-84.

-Magnus, Jan R., and Franc J. G. M. Klaassen. 1999. "On the Advantage of Serving First in a Tennis Set: Four Years at Wimbledon.” Journal of the Royal Statistical Society: Series D, 48(2): 247-56.

Manski, Charles F. 1995. Identification Problems in the Social Sciences. Cambridge, MA: Harvard University Press.

Morris, Larry W., Mark A. Davis, and Calvin H. Hutchings. 1981. "Cognitive and Emotional Components of Anxiety: Literature Review and a Revised Worry-Emotional Scale." Journal of Educational Psychology, 73(4): 541-55.

-Palacios-Huerta, Ignacio. 2003. "Professionals Play Minimax." Review of Economic Studies, 70(2): 395-415.

-Prendergast, Canice. 1999. "The Provision of Incentives in Firms." Journal of Economic Literature, 37(1): $7-63$.

Rauh, Michael T., and Giulio Seccia. 2006. "Anxiety and Performance: An Endogenous Learning-by-Doing Model.” International Economic Review, 47(2): 583-609. 